\title{
The Role of Smoke-Point in Material Flammability Testing
}

\author{
JOHN DE RIS \\ Factory Mutual Research Corporation \\ Nowood, MA 02062 USA \\ XIAO-FANG CHENG \\ University of Science \& Technology of China \\ Hefei, Anhui, China
}

\section{ABSTRACT}

It has been established that the release of both thermal radiation and products of incomplete combustion from well-ventilated buoyant turbulent diffusion-flames are well-correlated by the fuel's laminar flame smoke-point value. Thus the smoke-point of a material provides an important measure of its flammability. Standard methods are available for measuring the smoke-points of gaseous and liquid fuels, but not for solid fuels. The apparatus developed for the present study can be used for measuring the smoke-points of charring and noncharring solid fuels. A horizontal fuel sample is continuously fed into a downward pointing $\mathrm{CO}_{2}$ laser beam which pyrolyzes a small area of the sample. The heat release rate (or flame height) of the steady laminar flame produced by the pyrolysis gases is controlled by the laser beam power and/or the sample feed rate. The flame height is measured by a video camera while the release of smoke is measured by its attenuation of an electronically chopped infrared beam. The smoke-point is defined here by the critical flame height (or heat release rate) at which significant smoke is released from the flame tip. This smoke-point criterion occurs at considerably greater flame heights than the "equal-wings" condition, which previously has been used by some investigators to define the smoke-point.

KEYWORDS: Flammability Testing, Flame Radiation, Incomplete Combustion, SmokePoint, Soot.

\section{INTRODUCTION}

\section{Smoke-Point as Flammability Property}

It has been established ${ }^{1-4}$ that both the release of products of incomplete combustion and the release of thermal radiation from well-ventilated buoyant turbulent diffusion-flames (characteristic of fires burning in the open), are well-correlated by the fuel's laminar flame smoke-point value. Figure 1 shows the incompleteness of combustion, $\chi_{1}$, (heat of combustion of products divided by the fuel heat of combustion) for various fuels burning in air plotted against the fuel laminar smoke-point flame height ${ }^{2}$. The products of incomplete combustion typically consist of soot, tars, $\mathrm{CO}$ and other unwanted chemical compounds; so that knowledge of the smoke-point of a fuel gives a good indication of its total release of 
unwanted non-thermal products of combustion. Similarly, Figure 2 shows the radiant fraction, $\chi_{R}$ of the theoretical heat-release-rate for various fuels plotted against the rate of heat release of the fuel's laminar smoke-point flame ${ }^{3,4}$. This rate of heat release is generally proportional to the smoke-point flame height. The radiant fraction, $\chi_{R}$, is closely related to the flame radiant heat flux intensities which typically control fire spread rates and heat release rates per unit area of the fuel in (large) hazardous-scale fires. Thus, the smoke-point is also of major importance in assessing a fuel's flammability'. For turbulent flames, both $\chi_{1}$ and $\chi_{R}$ are insensitive to fire size (i.e., heat release rate), so that they are often regarded as material flammability properties which can be estimated from the fuel's smoke-point. As we discuss in more detail below, the smoke-point of a fuel provides a convenient measure of flame sootiness which governs the release of both radiation and unwanted products of incomplete combustion.

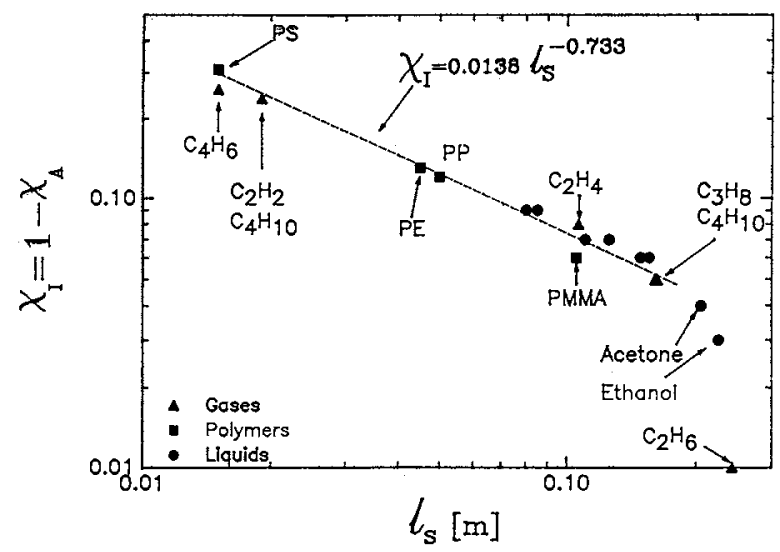

FIGURE 1. Incompleteness of combustion vs. smoke-point flame height ${ }^{2}$.

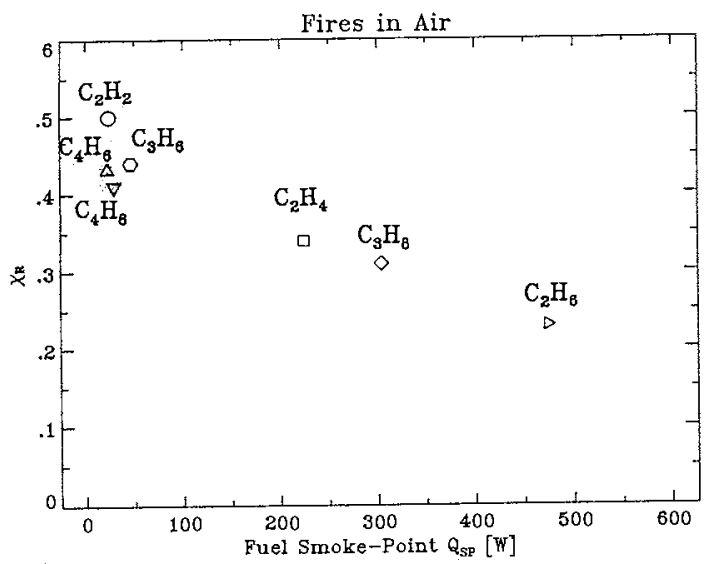

FIGURE 2. Radiant fraction from buoyant turbulent diffusion flames plotted against fue smoke-point heat release rate which is proportional to the smoke-point flame height ${ }^{3,4}$. 
The smoke-point of a fuel is generally defined by the critical laminar "candle-like" flame height (or heat release rate) at which smoke just begins to be released from the flame tip. In general, soot is formed in the lower part of the flame, transported by the rising gases, and oxidized in the upper part of the flame ${ }^{6}$. For laminar flames at their smoke-point, the competing mechanisms of soot formation and soot oxidation are in balance ${ }^{6}$. For flames burning at or below their smoke-point height the soot is completely oxidized in the upper part of the flame before it can escape. The fraction of fuel converted to soot increases with the residence-time of the fuel in the lower part of the flame where the as yet undecomposed fuel and fuel intermediates are still available ${ }^{6,7}$. The residence-time, and hence soot volume fraction and radiative heat loss per unit volume from the soot all increase with the fuel supply rate (or flame volume) ${ }^{6,7}$. With increasing fuel supply rate, the increased fractional radiative heat loss leads to increased cooling and the eventual quenching of the flame tip before all the soot and other product of incomplete combustion can be oxidized ${ }^{6,7}$. Fuels producing sootier flames have smaller critical smoke-point residence-times and correspondingly smaller smokepoint laminar flame heights, because the greater intensity of their radiative heat loss from the soot causes their flames to cool more rapidly, leading to earlier extinction by radiation ${ }^{6,7}$.

The chemical composition of soot is generally thought to be similar for all $\mathrm{C}-\mathrm{H}, \mathrm{C}-\mathrm{H}-\mathrm{O}$ and $\mathrm{C}-\mathrm{H}-\mathrm{N}$ fuels, so that their chemical mechanism of soot oxidation is presumably independent of fuel type ${ }^{6}$. This implies that the smoke-point of a fuel is primarily a measure of its soot formation rate. In the case of fuels containing halogens the soot oxidation mechanism is probably altered by the presence of the halogens $s^{8}$. The general cross-correlation of $\chi_{R}$ with $\chi_{\mathrm{I}}$ for both halogenated and non-halogenated fuels in turbulent fires suggests that this latter effect may not be important in practice.

In the case of buoyant turbulent diffusion flames the controlling flow (or residence) times of the individual flamelets are distributed over a range of times determined almost exclusively by the buoyant fluid mechanics ${ }^{10,11}$. For fuels having slow soot formation rates (i.e., large smoke-point heights), these flow times are typically sufficient to oxidize virtually all the soot and other products of incomplete combustion before the flamelets are quenched by radiative cooling (see Figure 1). On the other hand, the flamelets from fuels having rapid soot formation rates (i.e., short smoke-point heights) are more rapidly cooled by radiation, and are quenched before they can consume all the available soot. In the latter case, greater fractions of the supplied theoretical heat leaves the flames in the form of radiation and quenched products of incomplete combustion. This explains the general trends observed in Figures 1 and 2.

\section{Smoke-Point Measurement Methods}

Standard methods exist for measuring the smoke-points of gaseous and liquid fuels. The smoke-points of gaseous fuels are typically measured for fuels issuing from a simple tube $(0.5$ $-1.0 \mathrm{~cm}$ diameter) into a quiescent air environment or a gentle upward flowing ambient air stream capable of providing several times the stoichiometric oxidant requirement of the flame. Measured smoke-points depend weakly on the tube orifice diameter and the conductive heat loss to the burner tube ${ }^{12,13}$. It is sometimes necessary to surround the flame with screens to suppress vertical flame oscillations ${ }^{13}$. With ingenuity one can stabilize laminar smoke-point flames of arbitrarily large flame heights. 
The smoke-points of liquid fuels are sometimes measured by first vaporizing and then measuring them as gaseous fuels. More often their smoke-points are measured by letting the flame vaporize the liquid fuel from an adjustable wick prescribed by the ASTM D1322 method. ${ }^{14}$

The smoke-points of solid fuels have been measured by heating a fuel sample contained in an Erlemeyer flask ${ }^{2}$ or a small quartz vial ${ }^{15}$ having an open top through which the pyrolysis vapors can escape and support a "candle-like" laminar diffusion flame. The smoke-points of the solid fuels, shown in Figure 1, were measured by this technique ${ }^{2}$. The transient response of the solid sample to such heating makes it difficult to maintain steady pyrolysis rates and flame heights using this method. This problem could be overcome, in principle, by regulating the sample heating rate with a feedback controller which responds to the flame height.

The vial method has three disadvantages: (1) hot pyrolysis vapors come into contact with the surface near its exit where the vapors can be condensed, adsorbed or chemically decomposed; (2) the fuel sample must be cut up into one (or more) little pieces when put into the vial, making the method unsuited for inhomogenous fuels; (3) the technique is not well suited to charring fuels whose pyrolysis chemistry in batch mode is an inherently transient process.

The above problems are largely overcome in the present study by steadily feeding a horizontal sample of the original (inhomogenous) fuel into a downward directed, high intensity optical (laser) beam, so that the resultant pyrolysis gases rise from the sample surface and support the "candle-like" flame without contacting intervening surfaces.

\section{EXPERIMENTAL APPARATUS}

The apparatus, shown in Figure 3, is designed to produce a steady laminar "candle-like" diffusion flame rising from a material sample being steadily moved at a controlled rate into the path of an intense laser beam. The flame height is controlled by altering the sample feed rate and/or the laser beam power. The laser beam comes from an adjustable-power 10-50 W $\mathrm{CO}_{2}$ laser radiating at a wavelength of $10.6 \mu \mathrm{m}$. The $1 \mathrm{~mm}$ laser beam enters the enclosure from the right through an optical window, which prevents room drafts from entering the enclosure. The beam passes through the enclosure and exits the enclosure through a $12.5 \mathrm{~mm}$ diameter hole in the copper base plate and impinges upon the sample moving below the plate to produce a steady stream of pyrolysis gases which supply fuel to the vertical axisymmetric diffusion flame. The base of the flame typically spreads out to $5-10 \mathrm{~mm}$ in diameter before the rear of the attached flame is extinguished by coming into contact with the cold copper baseplate positioned immediately above the moving sample. The flame rises through a series of (10 cm O.D., $2 \mathrm{~cm}$ I.D.) annular stabilizing screens which suppress vertical oscillations. The flame is viewed from the front by a commercial color video camera/recorder which is focused onto two scales placed on either side of the flame. The height of the flame is evaluated after the test from still photographs taken from the video recording. Ample draftfree air is drawn into the enclosure through double layers of perforated (40\% open) metal sheets placed above and on two sides of the enclosure as shown. The flame product gases and smoke exit the enclosure through the central glass chimney. This enclosure design with its particular arrangement of screens provides correct smoke-point flame heights for gaseous fuels $\mathrm{C}_{2} \mathrm{H}_{4}$ and $\mathrm{C}_{3} \mathrm{H}_{6}$ in agreement with literature values ${ }^{8}$. 


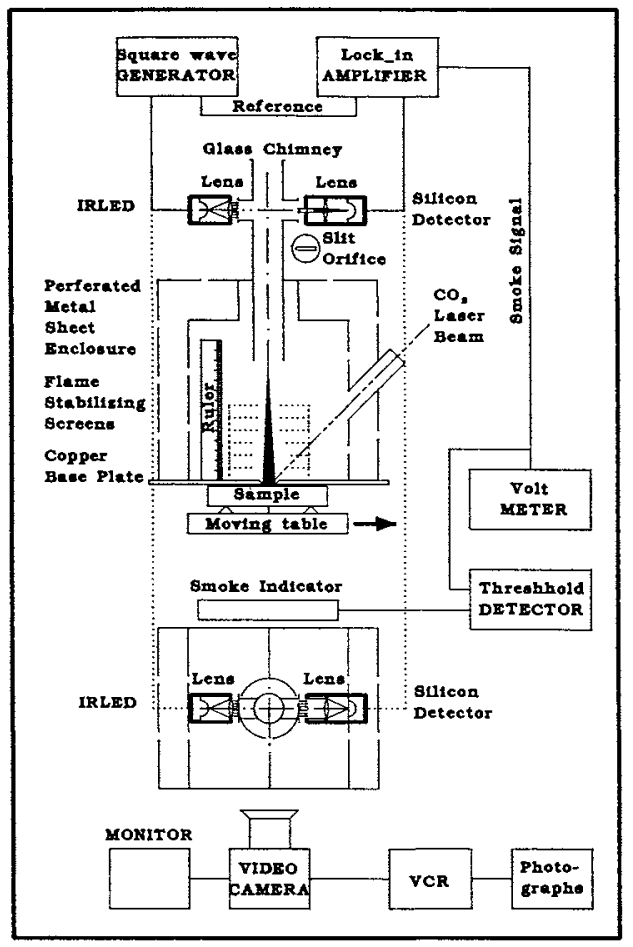

FIGURE 3. Smoke-point apparatus.

The smoke released by the flame is measured by its extinction (i.e., attenuation) of a horizontal infrared beam crossing the smoke column, as shown. A square-wave generator drives an infrared light emitting diode (IRLED) emitting at a wavelength of $0.94 \mu \mathrm{m}$. This wavelength is long enough to avoid scattering by the soot particles and short enough to avoid absorption by the $\mathrm{CO}_{2}$ and $\mathrm{H}_{2} \mathrm{O}$ gases being released by the flame. Using inexpensive commercial optical parts, the beam in sequence, is first collimated by a lens, passes through the chimney, through a horizontal slit orifice, and then focused onto a silicon detector/amplifier which is particularly sensitive to light at this wavelength. The horizontal slit orifice makes the signal insensitive to any lateral movement of the smoke column. As a result the beam attenuation is proportional to the total soot cross-section per unit height of the smoke-column. The optical system is kept clean of soot deposits by the natural convection of ambient air drawn into the upper chimney through the horizontal glass openings shown in the figure. The detector signal component which is in-phase with the square-wave generator, is resolved by a lock-in amplifier whose D.C. output signal is offset to make it proportional to the smoke attenuation. The attenuation signal is measured by a DVM and also supplied to a threshold detector which operates a set of colored lights seen by the video camera to record whether the flame is above or below its smoke-point. The optical system is readily calibrated in units of smoke column absorption cross-section per unit height by placing light absorbing wires of different diameters across the optical beam. 
To understand and interpret the "candle-like" flames in terms of the smoke-point we first measured the smoke release and visible flame heights for a series of ethene $\left(\mathrm{C}_{2} \mathrm{H}_{4}\right)$ and propene $\left(\mathrm{C}_{3} \mathrm{H}_{6}\right)$ flames over a range of flow rates, as shown in Figs. $4 \mathrm{a}$ and $4 \mathrm{~b}$. These gaseous fuels were supplied to the base of the apparatus through a $6 \mathrm{~mm}$ diameter stainless steel tube. Careful observation of the tip region of flames near their smoke-point reveals a central luminous core surrounded by a thin hollow cylinder of luminous soot which appears like two vertical wings when viewed from the side. The detached wings are not visible for flames considerably below their smoke-point, presumably because such flames are less sooty. As the flame height increases the wing tips become visible at a position slightly below the tip of the core flame (see Figs. $4 \mathrm{a}$ and $4 \mathrm{~b}$ ). With increasing fuel flow rate the height of the wings increases faster than the height of the core until they cross-over at the so-called "equal wings" condition. Because this "equal wings" condition can be precisely determined by eye, it has often been used, in the literature ${ }^{8,14}$, to denote the smoke-point. However, as seen in Figs. $4 \mathrm{a}$ and $4 \mathrm{~b}$, very little smoke is released at this condition. Apparently almost all the soot continues to be oxidized in the neighborhood of this condition.

Beyond the "equal wings' condition the height of the wings increase very rapidly with fuel flow rate and extends considerably beyond the central core ${ }^{16}$. Then, at a still higher flow rate the core height suddenly increases, merges with the wings, and begins to release smoke as shown in Figs. $4 \mathrm{a}$ and $4 \mathrm{~b}$. We define this latter condition as the smoke-point, because it is where significant smoke actually begins to be released. In practice, the experimental smokepoint can be precisely defined by the intercept of the measured smoke release rate with the abscissa, as shown in Figure 4a. This procedure can be performed automatically by software without requiring any delicate visual judgement of the flame condition. ${ }^{16}$

The different slopes (of flame height versus heat release rate) below and above the "equalwings" condition in Figs. $4 \mathrm{a}$ and $4 \mathrm{~b}$ suggest a change in controlling mechanism. Below the "equal-wings" condition the flame height is effectively proportional to the fuel flow rate; and is controlled by the time needed by the oxygen to diffuse into and fully oxidize the supplied fuel and its decomposition products. Roper ${ }^{17}$ successfully explained this proportionality by a diffusion flame model which assumes infinitely fast chemical kinetics.

Above the "equal-wings" condition the required oxygen remains proportional to the fuel flow rate, while the available oxygen increases approximately proportional to the flame height (as it does below the "equal-wings" condition). Thus, there is more than enough available oxygen in the upper regions to consume the soot, so that the persistence of luminous soot implies that its consumption rate is controlled by finite rate soot oxidation kinetics. In the region between the "equal-wings" condition and the smoke-point the finite soot oxidation rate is apparently sufficient to consume virtually all the available soot, whereas above the smokepoint the cooling by radiation reduces the soot oxidation rate to the point of becoming insufficient to consume all the soot, resulting in the release of some soot.

The phenomenon of wings and their complicated behavior can be explained by the much larger measured particle sizes of the soot in the wings as compared to the central core. The soot in the wings originates from just inside the flame sheet near the base of the flame where temperatures are near their maximum. The rapid formation in this region produces very high soot volume fractions, rapid agglomeration of soot particles, large particles having large volume to surface area ratios, and ultimately longer soot oxidation times. The central core 


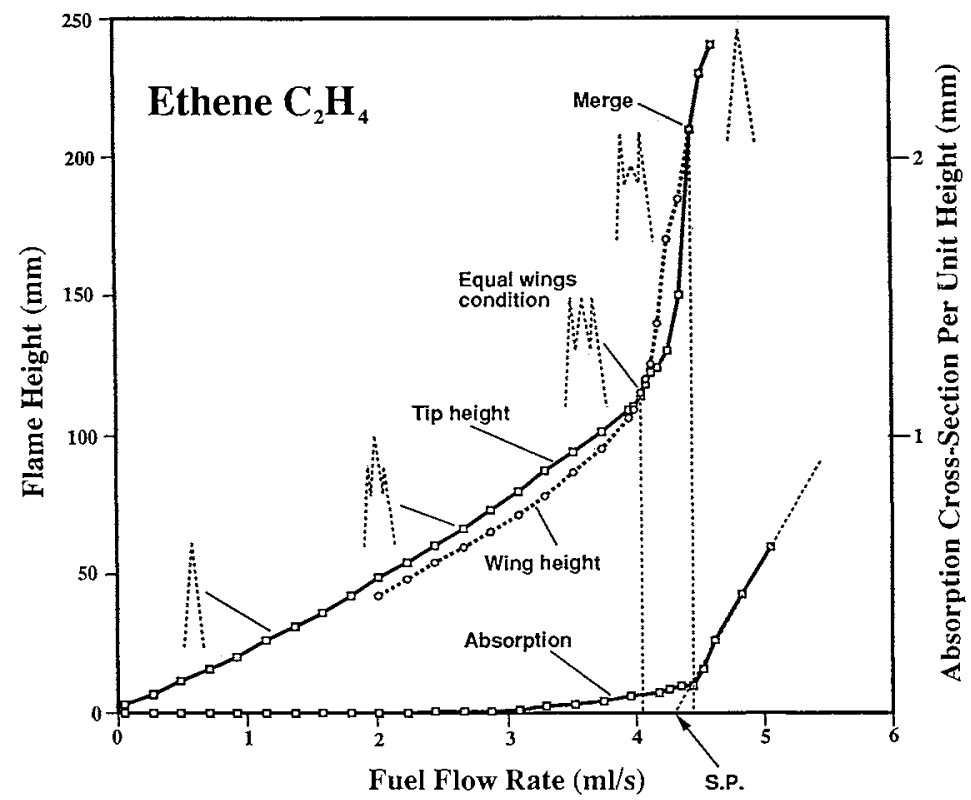

(a)

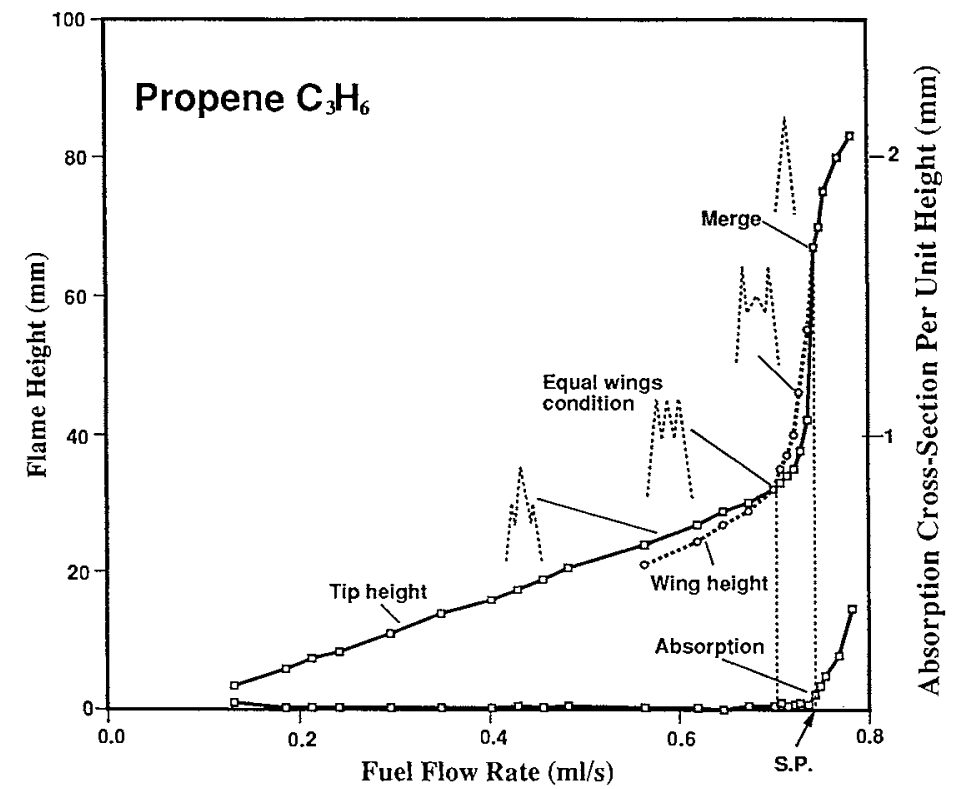

(b)

FIGURE 4. Core and wing flame height vs. fuel supply rate (a) ethene $\mathrm{C}_{2} \mathrm{H}_{4}$, (b) propene $\mathrm{C}_{3} \mathrm{H}_{6}$. Note profuse release of soot when core flame finally penetrates through lines. 
soot forms across the entire flame interior volume somewhat higher up, resulting in a much lower local soot volume fraction, but occupying a considerably larger total volume. The emergence (or apparent separation) of the wings from the central core somewhat beneath the flame tip is evidence of significant soot oxidation taking place just inside the wing cylinder, where the smaller soot particles in the outer part of the core are virtually eliminated because of their much shorter oxidation times. The rapid increase of the height of the wings with increasing fuel supply rate near the "equal wings" condition can be explained by the longer oxidation times of the particles in the wings. The slower increase in the core height in this region can be attributed to the large surface area to volume ratio of the core soot being sufficient to consume almost all the available oxygen. For higher fuel supply rates the radiant heat loss eventually reduces the: temperature, chemical kinetic controlled surface oxidation rates, and heat release rate in the central core, causing a rapid extension of the core and release of a significant amount of soot.

The separation between the "equal wings" condition and the smoke-point depends empirically on both the fuel type and ambient oxygen concentration. That is, the ratio of the fuel flow rates at these two conditions depends on fuel type and ambient oxygen concentration. Markstein ${ }^{16}$ observes that the wings tend to disappear for ambient oxygen concentrations considerably less than that of air, leading to a convergence of the "equal-wings" and smokepoint conditions. Conversely for enhanced ambient oxygen concentrations the wings become dominant and the "equal-wings" condition occurs much earlier than the smoke-point ${ }^{16,18}$. In this case the wings become greatly elongated and can even release considerable smoke before the central core rises and merges with the wings ${ }^{18}$. The explanation of the previous paragraph suggests that an increase in ambient oxygen concentration increases the soot particle sizes of the wings more than the core.

In summary, the "equal wings" condition marks the transition from diffusion controlled to kinetic controlled mechanism of soot oxidation and should not be interpreted as the smokepoint at which smoke is actually released by the flame.

\section{SMOKE-POINTS OF SOLID FUELS}

Figure 5 shows the flame heights and corresponding smoke releases for black PMMA (polycast) samples moving at various speeds while being subjected to various laser power levels. One sees that the flame heights increase with increased imposed laser power at a fixed translation speed. The increase in laser power results in more fuel vaporization, higher flames, and for flames above their smoke-point greater smoke release rates.

One also sees that the flame heights and smoke release rates decrease with increased translation speed at each affixed laser power. This decrease can be explained by considering the net energy available for fuel vaporization. Both the laser and the attached flame deliver their power to the sample surface. Some of the delivered power goes directly toward fuel vaporization, while the remaining thermal power is conducted into the sample interior to heat it up to its vaporization temperature. Some of this latter thermal power is lost to the system as the sample material is convected beyond the exposed hole in the copper base plate. The thermal power lost by solid convection increases with increased translation speed, resulting in less power available for fuel vaporization, lower flame heights, and for flames above their smokepoint, less smoke release. 


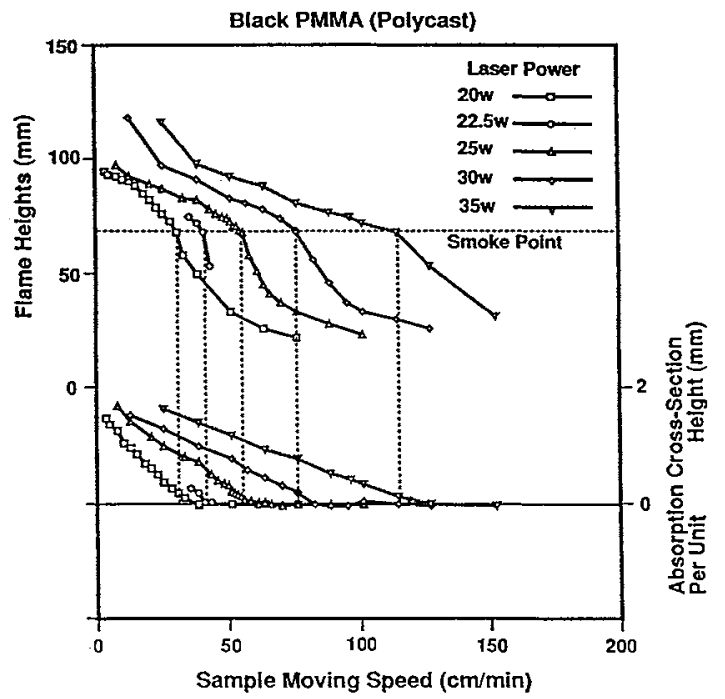

FIGURE 5. Flame height (upper curves) and smoke release (lower curves) vs. sample feed rate at various laser beam powers. Dotted lines correspond to flames at smoke-point.

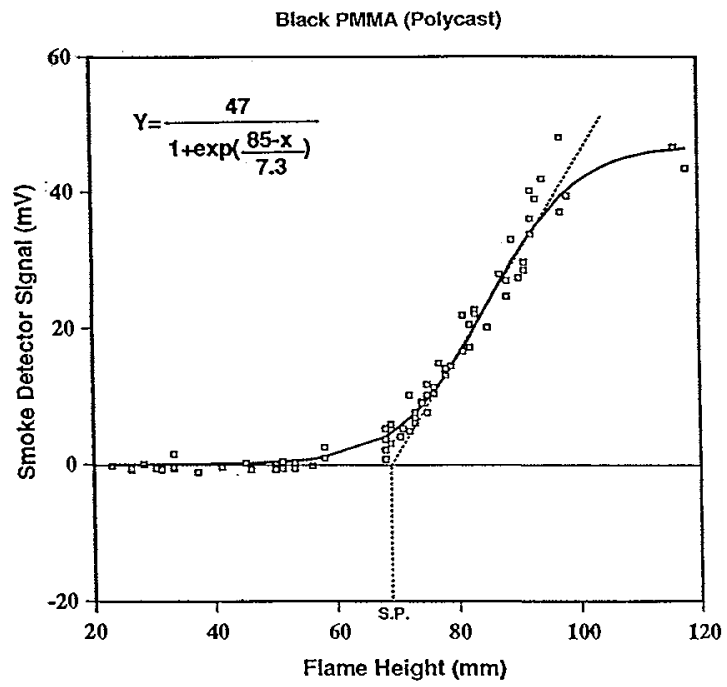

FIGURE 6. Correlation of smoke-release vs. flame height for black PMMA samples subjected to various laser powers while moving at various speeds. 
All the dotted lines in Figure 5 delineate to the smoke-point condition. It is important to notice that at the smoke-points all the flame-heights are equal and do not depend on the specific laser power.

Figure 6 shows the same black PMMA data cross-plotted according to smoke-release versus flame-height. The correlation of all the data on a single curve implies that the smoke release is solely dependent on the flame height independent of the specific combination of laser power and translation speed used to produce the flame. The existence of such a correlation suggests that the smoke-point measurement is apparatus independent, as least insofar as laser power and translation speed are concerned.

The logistic function, shown in Figure 6, provides a "best-fit" to the correlated data. The smoke-point is obtained from the intersection of the maximum slope of this logistic curve with the abscissa. This is the same smoke-point shown by the dotted lines in Figure 5.

Figure 7 shows a similar data correlation for particle board material which chars instead of simply vaporizing like PMMA. The Particle Board data were obtained over a similar range of translation speeds but with about double the laser power levels used for PMMA. The

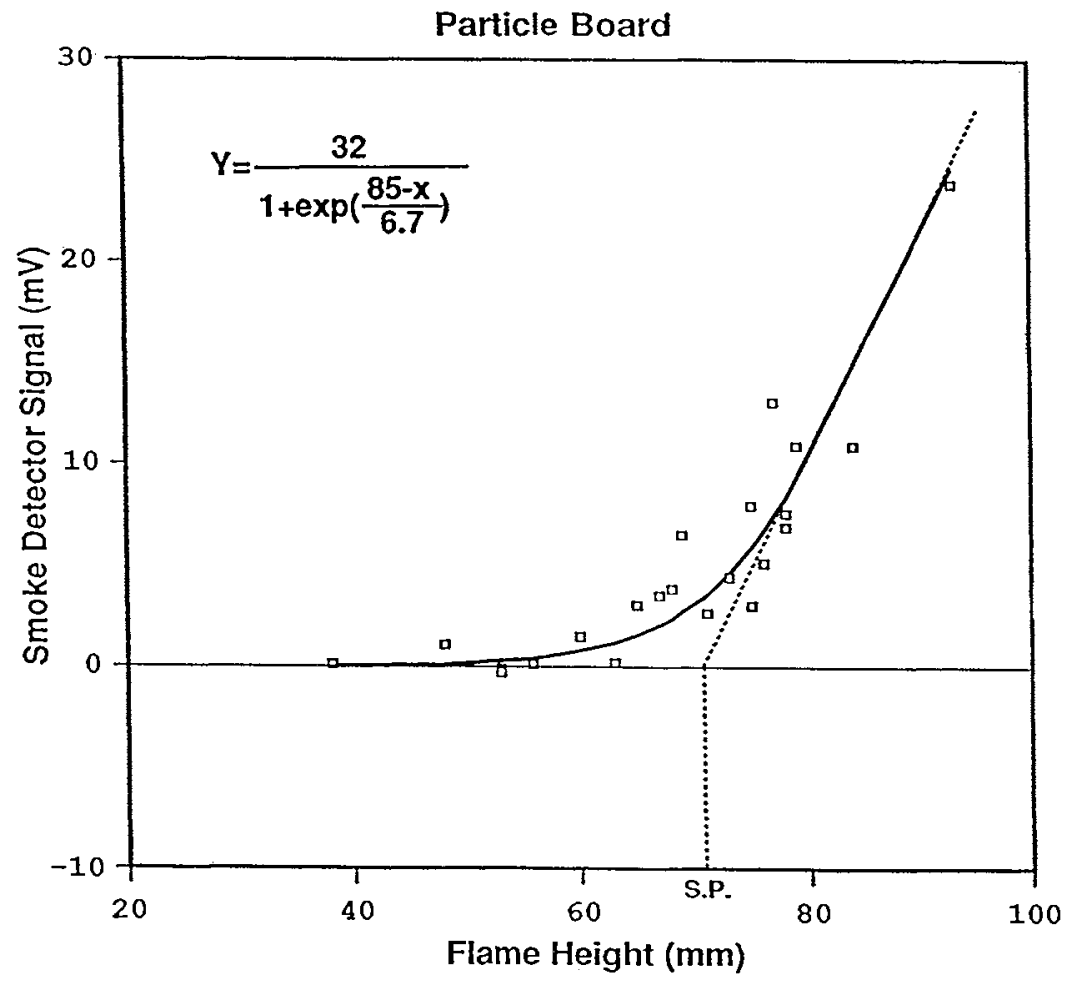

FIGURE 7. Correlation of smoke-release vs. flame height for charring particle board samples. 
increased scatter of the data is due principally to inhomogenities of the particle board density near its heated surface. Nevertheless, one can evaluate its smoke-point with reasonable precision after fitting the data to the logistic function, as shown.

The smoke-points of black PMMA and Particle Board obtained here by the laser technique are about $40 \%$ smaller than previous measurements for the same fuels obtained ${ }^{15}$ by the heated vial technique. This difference may be due to: (1) heated air rising from the heated vial; (2) alteration of fuel vapors coming into contact with the exit of the heated vial; (3) the very high rate of solid heating $\left(50 \mathrm{~W} / \mathrm{cm}^{2}\right)$ by the laser beam; or possibly (4) absorption of the $\mathrm{CO}_{2}$ laser radiation by $\mathrm{CO}_{2}$ in the product gases near the base of the flame. This latter problem of laser absorption by the product gases could be avoided by using a Nd: YAG power laser radiating at a wavelength of $1.06 \mu \mathrm{m}$. Recently Nd: YAG lasers have become quite affordable.

\section{CONCLUDING REMARKS}

The most important findings described here are:

1. The smoke-point of a fuel determines: (1) its flame radiant fraction which controls fire spread rates and peak heat release rates of large-scale fires; as well as 2) its incompleteness of combustion which controls the fractional release of smoke, $\mathrm{CO}$ and other unwanted nonthermal products of combustion. Thus the smoke-point provides a convenient measure of a fuel's large-scale fire hazard.

2. The smoke-point of both charring and non-charring solid materials can be conveniently measured by translating material samples across the path of an intense optical beam to produce a steady stream of pyrolysis gases supporting a "candle-like" flame. The convenience of the method is illustrated by the fact that after we developed our techniques all solid fuel flame measurements reported here were obtained in a period of four hours using a rented $\mathrm{CO}_{2}$ laser.

3. A careful study of the central core and wing tip flame heights and smoke release from gaseous ethene, $\mathrm{C}_{2} \mathrm{H}_{4}$, and propene, $\mathrm{C}_{3} \mathrm{H}_{6}$, flames reveals that the smoke-point (i.e., point of significant smoke release) occurs for flame heat release rates somewhat above the "equalwings" condition often reported as the smoke-point in the literature. The corresponding flame heights at the actual smoke-point are considerably greater than the "equal wings" flame heights. Because of the non-linear relationship between the flame height and heat release rate above the "equal-wings" condition, it would be better to measure and report the smoke-point in terms of the flame's heat release rate rather than the flame height. The heat release rate could be measured electronically using the oxygen depletion (of product gases) method; so that, when combined with an electronic measurement of the smoke release, one could identify the smoke point of a material without requiring visual judgment of the flame.

4. We suggest that a future smoke-point measurement apparatus use a shorter wavelength optical beam (perhaps Nd: YAG laser or a focused quartz-halogen lamp) instead of the $\mathrm{CO}_{2}$ laser source, as was used in this study. Some of the imposed 10.6 micron radiation from the $\mathrm{CO}_{2}$ laser may have been directly absorbed by $\mathrm{CO}_{2}$ in the flame gases in our study, increasing soot formation rates in the lower part of the flames, and causing our measured smoke-points 
of PMMA and particle board to be considerably (40\%) smaller than previous heated vial smoke-point measurements for these same fuels.

\section{REFERENCES}

1. Markstein, G.H., Twentieth Symp. (Int.) on Combustion, The Combustion Institute, Pittsburgh, PA, p 1055, 1985.

2. Tewarson, A., "Smoke-Point Height and Fire Properties of Materials," FMRC Technical Report J.I. OK3R3.RC, Factory Mutual Research Corporation, Norwood, MA 1988.

3. Orloff, L., de Ris, J. and Delichatsios, M.A., Combust. Sci. and Tech., Vol. 84, pp 177$186,1992$.

4. de Ris, J., and Orloff, L., submitted to Comb. and Flame.

5. de Ris, J., Seventeenth Symp. (Int.) on Combustion, The Combustion Institute, Pittsburgh, PA, p. 1003, 1979.

6. Kent, J.H., Comb. and Flame, 63, pp 349-358, 1986.

7. Markstein, G.H., and de Ris, J., Twentieth Symposium (Int.) on Combustion, The Combustion Institute, Pittsburgh, PA, pp 1637-1646, 1984.

8. Schug, K.P., Manheimer-Timnat, Y., Yaccarino, P., and Glassman, J., Comb. Sci. and Tech., 22 , p 235, 1980.

9. Tewarson, A., Private Communication.

10. Sivathanu, Y.R. and Faeth, G.M.: Combustion and Flame, 81, pp 133-149, 1990.

11. Koylu, U.O. and Faeth, G.M., Combustion and Flame $\underline{81}$, pp 61-76, 1991.

12. Markstein, G.H., Twenty-First Symposium (Int.) on Combustion, The Combustion Institute, p 1107, 1987.

13. Kent, J.H. and Wagner, H.Gg., Combustion Sci. and Technology, 41, pp 245-269, 1984.

14. ASTM, Standard Test Method for Smoke-Point of Aviation Fuels," pp. 727-735, Designation D1322-75 (Reapproved 1980.

15. Delichatsios, M.A., Fire Safety Journal 20, pp 299-311, 1993.

16. Markstein, G.H., Twenty-Second Symposium on Combustion, The Combustion Institute, Pittsburgh, PA, p 363, 1989.

17. Roper, F.G., Comb. and Flame 29, p 219, 1973.

18. Glassman, J. and Yaccarino, P., Comb. Sci. and Tech., 24, p 107, 1980. 